\title{
Bullying and Victimization: The Effect of Close Companionship
}

\author{
Sabine A. M. Veldkamp, ${ }^{1,2}$ Elsje van Bergen, ${ }^{1,2,3}$ Eveline L. de Zeeuw, ${ }^{1,2}$ Catharina E. M. van \\ Beijsterveldt, ${ }^{1}$ Dorret I. Boomsma, ${ }^{1,2,4}$ and Meike Bartels ${ }^{1,2,4}$ \\ ${ }^{1}$ Department of Biological Psychology, Vrije Universiteit Amsterdam, Amsterdam, the Netherlands \\ ${ }^{2}$ EMGO+ Institute for Health and Care Research, VU University Medical Center, Amsterdam, the Netherlands \\ ${ }^{3}$ Department of Experimental Psychology, University of Oxford, Oxford, UK \\ ${ }^{4}$ Neuroscience Campus Amsterdam, Amsterdam, the Netherlands
}

\begin{abstract}
Peer bullying and victimization are a widespread phenomenon among school-age children and can have detrimental effects on the development of children. To examine whether having a close companion during childhood increases or decreases risk of victimization and bullying, this study compared twins to singleton children. A large group of twins $(n=9,909)$ were included who were compared to their related non-twin siblings ( $n=1,534$ ) aged 7-12 from the Netherlands Twin Register, thus creating optimal matching between twins and non-twins. Bullying and victimization were each based on a four-item scale filled out by their teachers. Prevalence rates for either bullying or victimization did not differ between twins and singletons. In total, in the past couple of months, $36 \%$ of children bullied peers moderately to severely, and $35 \%$ suffered moderately to severely from victimization. Boys were more likely to bully and were more prone to becoming a victim than girls. The most notable finding is that female twin pairs placed together in the same classroom did not bully more often, but were victimized less often, thus pointing to a protective effect of having a close companion in the classroom.
\end{abstract}

Keywords: bullying, victimization, twins, singletons, classroom sharing

Peer bullying, a widespread phenomenon among schoolage children, can have detrimental consequences on childhood development. Both bullies and victims of bullying suffer more from a variety of problems than their uninvolved peers, including psychosomatic problems (Gini \& Pozzoli, 2009), low self-esteem, anxiety, depression, loneliness, and low social self-concept (Hawker \& Boulton, 2000). Consequently, this topic has attracted a lot of attention from educational practitioners, mental health services, and academics. This study compares the prevalence rates of bullying and victimization in twins and singletons to learn something about the potentially protective effects of having a close peer companion during childhood.

It still remains an open question whether children with a close peer companion - for example, twins - are at higher, lower, or similar risk for bullying and victimization. One might, on the one hand, think that these strong companionship dyads are more vulnerable to be victimized than singletons. For example, Hay and Preedy (2006) suggest that the strong relationship in twins might restrict the interaction with other children. Research indeed showed that twins show less prosocial behavior than singletons when they play with an unfamiliar peer (DiLalla, 2006), which could make twins more often the target of peer victimization. On the other hand, it is well known that the presence of friends protects children from being bullied (Goldbaum et al., 2003; Hodges et al., 1999), and it seems that sibling relationships provide protection against peer bullying as well (Lamarche et al., 2006).

To our knowledge, only three studies have been carried out to detect twin-singleton differences and all three only looked at victimization (Barnes \& Boutwell, 2013; Oshima et al., 2010; Weissenberg et al., 2007). The results of these studies are contradictory. Barnes and Boutwell (2013) found that singletons are at higher risk, whereas Weissenberg et al. (2007) found the opposite effect, and Oshima et al. (2010) reported no effect at all. It should be noted that all these studies were based on unrelated singletons, meaning that the twin and singleton samples may differ on

RECEIVED 20 October 2016; ACCEPTED 7 November 2016

ADDRESS FOR CORRESPONDENCE: Sabine A. M. Veldkamp, Department of Biological Psychology, Vrije Universiteit Amsterdam, De Boelelaan 1105, 1081 HV, Amsterdam, the Netherlands. E-mail: s.a.m.veldkamp@vu.nl 
important family background factors, which hampers twinsingleton comparisons. Furthermore, the latter two studies suffered from low power ( $n=341$ and $n=72$, respectively). In contrast, we employed a large sample $(n \approx 10,000)$ of twins and their non-twin siblings, making them closely matched on family background. Importantly, the three previous studies solely focused on victimization. Our study is the first to examine twin-singleton differences in bullying as well. For bullying, we might speculate that twins are more involved than singletons. Twins have a pal with whom they could bully together, which is not the case for singletons.

Questions also remain about whether bullying in twins depends on twin-specific characteristics, such as the pair's zygosity and gender composition. Studies so far have shown no effect of zygosity on the proportion of bullies and victims in twins (e.g., Ball et al., 2008; Brendgen et al., 2008; Lamarche et al., 2007; Shakoor et al., 2015). However, it is still unknown whether the prevalence of bullying is affected by the gender composition of the pair (same gender or mixed gender) and whether this effect changes as children age. Given that children increasingly play with samesex peers (Rose \& Rudolph, 2006), it might be hypothesized that the effect of gender composition is absent in the beginning and is present at the end of primary school.

All the potential twin-specific influences discussed so far are not malleable, but whether a twin pair attends the same or different classrooms is usually a choice. Hence, an important question for education is whether the risk of bullying in twins is related to whether or not they attend the same classroom, and whether that effect differs for monozygotic (MZ) and dizygotic (DZ) twins. The previously mentioned effects for twins may be more pronounced for twin pairs placed in the same classrooms. Twins in the same classroom always have their close relative by their side, which can give them support and protect them from being bullied. Classroom sharing might, therefore, have a protective effect regarding victimization. We hypothesized that this effect might be stronger for $M Z$ twins, since they tend to be more attached to each other than are DZ twins (Tancredy \& Fraley, 2006). There is one relatively small study so far that has addressed this classroom-sharing question, suggesting that class sharing might protect against victimization (Lamarche et al., 2006). In the current study, this previous finding was tested in a 20-times larger sample to overcome power issues. Classroom sharing might also affect the proportion of bullies, because twins in same classrooms can bully classmates together. To our knowledge, previous research has not addressed this issue. This study, therefore, tested classroomsharing effects in bullying as well.

In previous research, some non-twin specific characteristics have been tested, namely gender and age. Most studies show that boys are more likely to bully than girls (e.g., Bowes et al., 2013; Kokkinos \& Antoniadou, 2013; Von Marées \& Petermann, 2010). An explanation for why boys are more prone to be bullies than girls is that they are generally more aggressive. Aggression is the overarching concept of which bullying is a subset (Griffin \& Gross, 2004). For victimization, findings are less consistent. There is also no agreement about the trend of bullying and victimization during primary school. Some studies show that the prevalence rate of bullying rises as children age (Atik \& Güneri, 2013), whereas others show the opposite or no clear effects at all (e.g., Camodeca et al., 2002; Pellegrini \& Long, 2002).

First, the current study investigated whether twins are at higher, lower, or similar risk compared to their nontwin siblings for both bullying and victimization. Second, this study tested whether the risk for bullying and victimization differs for $M Z$ versus DZ twins, same-sex versus opposite-sex twins, and twins attending the same versus separate classes. Meanwhile, age and gender effects were investigated. Third, it explored whether a possible classroom effect differs for MZ and DZ twins and whether the effect of gender composition changes over time.

\section{Method}

\section{Participants}

The current study used participants from the Netherlands Twin Register (NTR) (van Beijsterveldt et al., 2013). The NTR was established by the Department of Biological Psychology at the Vrije Universiteit Amsterdam. The reported project was approved by the medical ethical committee of the Vrije Universiteit Amsterdam (NTR/25-05-2007). Parents of the twins, aged 7, 9-10, and 12 years, were asked for their consent to approach the teachers of the twins and their non-twin siblings with a survey. Since 2010, the survey for the primary school teachers has included items on bullying and victimization. The current study includes data collected between 2010 and 2015. A subset of the final sample of twins and singletons had data on two (twins: $n=1,579$ individuals; siblings: $n=162$ ) or three (twins: $n=92$ individuals; siblings: $n=1$ ) time points due to the longitudinal data collection protocol. Multiple time points were included as multiple cases, while statistically controlling for their nonindependence (see section Statistical Analyses).

The twins and siblings were born between 1997 and 2008. The following figures refer to number of data points, not individuals. Surveys of twins were excluded if twin zygosity was unknown $(n=193)$, if they were filled out by someone other than the regular teacher $(n=81)$, if familiarity with the student was below average $(n=74)$, if the survey was filled out by the same teacher while the twins were in separate classes $(n=11)$, or if twin pairs attending the same class were rated by different teachers $(n=108)$. This resulted in a total twin sample of 10,063 cases for the calculation of bullying and victimization scores. This sample included mostly cases for twin pairs for whom data was available for both twins ( $n=4,337$ pairs). Incomplete data $(n=1,389)$ were mostly due to only one of the teachers 
returning the survey (when twins were in separate classes, $n=1,230)$. In addition, sibling data $(n=1,534)$ were included in order to compare the prevalence rates of bullying and victimization for twins and singletons. Subsequently, surveys were excluded when there were more than two missing values on the bullying and victimization scale, described in the measurement section $(n=167, n=154$, respectively). This resulted in a total sample of 9,896 cases for bullying and 9,909 cases for victimization. Only a few twins $(n=73)$ and siblings $(n=10)$ had a missing value on one of the traits. The age of the twins ranged from 6.52 to 12.94 years $(M=9.49, S D=2.01)$; for the siblings this was $4.68-$ 13.43 years $(M=9.99, S D=1.67)$.

\section{Measurements}

Bullying and victimization were measured by four items each, scored on a five-point scale: from 0 (never), 1 (once or twice), 2 (two or three times a month), 3 (about once a week), and 4 (several times a week). The items for victimization assessed (1) 'how often has the child been victimized in the past couple of months? (in general)', (2) 'how often has the child been teased, laughed at, or called names in the past couple of months? (verbal victimization)', (3) 'how often has the child been physically victimized, such as being hit, kicked, and pushed in the past couple of months? (physical victimization)', and (4) 'how often has the child been excluded by other children, ignored, or have other students spread false rumors? (relational victimization)'. Bullying was assessed with the same items, but in the perpetration form (see Jansen et al. (2012)). The total score of both phenotypes could range from 0 to 16 .

The reliability of the questions was good for both bullying $(\alpha=0.84)$ and victimization $(\alpha=0.80)$. Sum scores were computed when there was at most one missing item for a scale. Other missing items were imputed by the rounded averaged-item score of the scale for that child. The sum scores had an 'L'-shaped distribution, which was divided into three categories to determine the prevalence rates of bullying and victimization. The first category for both bullying and victimization was defined by a sum score of zero and was labeled as 'never bullied/was never victimized'. The second category was defined by a sum score of 1 or 2 , ranging from (very) mild to moderately bullied/victimized and was labeled as 'moderately bullied/was moderately victimized. The last category was defined by a score of at least 3 and ranged from substantial to very severe, labeled as 'severely bullied/was severely victimized'. A score of 3 means that someone scored 'once a week' on one of the four items. In subsequent statistical analyses, raw item data was used to avoid bias in parameter estimates due to nonnormality of the sum scores. The four items for bullying and victimization were combined into factor scores for each child. Simultaneously, the factorial level of the model was used to explain the effects of our predictors on bullying and victimization.

\section{Statistical Analyses}

Data were prepared in the statistical software $R$, version 3.2.0 ( $\mathrm{R}$ core team, 2015) and analyzed in Mplus version 6 (Muthén \& Muthén, 1998-2012). To accommodate multiple testing, we used adjusted $p$ values according to the Holm-Bonferroni method (Holm, 1979). This method is a less strict correction for multiple testing than the Bonferroni method. It is a sequential procedure that uses a less strict rejection criterion for each subsequent comparison to reduce the Type II (false negative) errors. Type II errors arise from decreasing Type I errors in multiple testing.

Twins and siblings came from the same family and thus were well matched for confounders. To correct for nonindependent observations, which results in underestimated standard errors when not taken into account, the analyses were corrected by using tests based on the sandwich or $\mathrm{Hu}$ ber/White variance estimator (Williams, 2000). The subset of children that had data on multiple time points was also used in the analyses, since the sandwich variance estimator also corrected for this dependency.

The statistical analyses included descriptive statistics on prevalence rates for the total sample, as well as for twins versus singletons, boys versus girls, $\mathrm{MZ}$ twins versus $\mathrm{DZ}$ twins, and twins attending same versus separate classrooms. Subsequently, main and interaction effects were statistically tested.

\section{Main Analyses}

To test for differences in prevalence rates for the different subgroups, a regression was performed. First, it was tested whether twins are at higher, lower, or similar risk compared to their non-twin siblings for both bullying and victimization.

Second, it was tested whether the risk for bullying and victimization differs for $\mathrm{MZ}$ and $\mathrm{DZ}$ twins, same-sex versus opposite sex-twins, and whether the risk is lower if twins attend the same or separate classrooms. At the same time, age and gender effects were investigated.

The second model included the main effects of age (both linear and curvilinear), classroom sharing, gender, and zygosity. One variable that indicates whether the twins are of same or opposite sex was added as a covariate to correct for confounding gender effects in the zygosity variable, as DZ pairs can and $\mathrm{MZ}$ pairs cannot be of mixed genders. The age predictor variables in the model were entered as meancentered continuous variables, whereas the other variables were entered as dichotomous variables.

In previous research, it has been shown that classroom assignment is associated with socio-economic status (SES) and externalizing problems (van Leeuwen et al., 2005). If an effect of classroom sharing were to be found, the model would be extended with the possible confounders SES and externalizing and internalizing problems to see whether the outcome changes. Data on these variables at age three, that is, before children went to school, are present for two-thirds 
TABLE 1

Prevalence Rates of Bullying and Victimization

\begin{tabular}{|c|c|c|c|c|c|c|c|c|}
\hline & \multicolumn{4}{|c|}{ Bullying } & \multicolumn{4}{|c|}{ Victimization } \\
\hline & $n$ & Never (\%) & Moderate (\%) & Severe (\%) & $n$ & Never (\%) & Moderate (\%) & Severe (\%) \\
\hline Total sample & 11,430 & 63.8 & 20.3 & 15.9 & 11,441 & 65.2 & 22.2 & 12.6 \\
\hline \multicolumn{9}{|l|}{ Twins versus sibs } \\
\hline Twins & 9,896 & 63.7 & 20.2 & 16.1 & 9,909 & 65.4 & 22.0 & 12.6 \\
\hline Singleton & 1,534 & 64.1 & 21.1 & 14.8 & 1,532 & 63.6 & 23.3 & 13.1 \\
\hline \multicolumn{9}{|l|}{ Gender } \\
\hline Boys & 4,985 & 56.2 & 22.9 & 20.9 & 4,988 & 62.2 & 23.1 & 14.6 \\
\hline Girls & 4,911 & 71.4 & 17.5 & 11.2 & 4,921 & 68.7 & 20.8 & 10.5 \\
\hline \multicolumn{9}{|l|}{ Zygosity } \\
\hline $\mathrm{MZ}$ & 3,725 & 65.2 & 19.3 & 15.5 & 3,735 & 67.3 & 20.9 & 11.8 \\
\hline DZ & 6,171 & 62.8 & 20.7 & 16.4 & 6,174 & 64.3 & 22.7 & 13.0 \\
\hline \multicolumn{9}{|l|}{ Class } \\
\hline Same class & 5,111 & 64.5 & 19.7 & 15.8 & 5,116 & 68.1 & 20.6 & 11.3 \\
\hline Different class & 4,677 & 62.8 & 20.8 & 16.4 & 4,684 & 62.2 & 23.7 & 14.1 \\
\hline
\end{tabular}

TABLE 2

Influences of the (Non) Twin-Specific Factors on Bullying $(n=9,788)^{\text {a }}$

\begin{tabular}{|c|c|c|c|c|c|c|}
\hline \multirow[b]{2}{*}{ Covariates } & \multicolumn{2}{|c|}{ Coding } & \multirow[b]{2}{*}{$\beta$} & \multirow[b]{2}{*}{ SE } & \multirow[b]{2}{*}{$p$-value } & \multirow[b]{2}{*}{$\alpha$-level ${ }^{b}$} \\
\hline & 0 & 1 & & & & \\
\hline Gender & Male & Female & -0.460 & 0.030 & $<.001$ & 0.008 \\
\hline Zygosity & $\mathrm{MZ}$ & $\mathrm{DZ}$ & 0.020 & 0.038 & .601 & - \\
\hline Class & Different & Same & -0.030 & 0.030 & .315 & - \\
\hline Same-sex & Same & Opposite & 0.055 & 0.037 & .139 & $0.013(N S)$ \\
\hline Age & \multicolumn{2}{|c|}{ Continuous variable } & 0.008 & 0.008 & .284 & \\
\hline Age squared & \multicolumn{2}{|c|}{ Continuous variable } & -0.018 & 0.004 & $<.001$ & 0.010 \\
\hline
\end{tabular}

Note: $S E=$ standard error, $N S=$ not significant. ${ }^{a} n=108$ missing values on class-variable.

${ }^{b}$ Corrected $\alpha$ level according to the Holm-Bonferroni method (Holm, 1979).

of our full sample (see van Leeuwen et al. (2005), for measurement details).

\section{Interaction Analyses}

If a classroom-sharing effect were to be found, a simplified model would be fitted to test whether the effect of classroom sharing differs for being a girl-girl, boy-boy, or oppositesex twins. To test this interaction effect, the covariates gender composition (same-sex vs. opposite-sex), gender, and zygosity were deleted from the main model to test this interaction effect fairly. In addition, the variable that specifies the type of twin pair was added as two dummy variables in the two interaction terms with classroom placement. The first dummy variable was coded 1 for girl-girl twins, and the second coded 1 for opposite-sex twins, leaving the boyboy twin pairs to represent the reference group.

In the follow-up analyses, we first examined whether gender composition (same-sex vs. opposite-sex) interacts with age in predicting bullying and victimization. By adding this interaction term, it was tested whether the effect of being a same-sex versus opposite-sex twin on bullying and victimization changes as children age. In addition, it was tested whether the effect of attending the same versus separate classrooms was different for MZ and DZ twins. The main effects were still included in the model to correct for possible confounding effects.

\section{Results}

\section{Descriptive Statistics}

Table 1 presents the prevalence rates of bullying and victimization for the total sample, for twins versus singletons, boys versus girls, $\mathrm{MZ}$ versus $\mathrm{DZ}$ twins, and twins in same versus separate classes. As can be seen, $36.2 \%$ of the total sample (including twins and siblings) has bullied others, whereas $34.8 \%$ has been victimized in the past couple of months.

\section{Main Analyses}

Twins did not differ significantly from singletons with respect to bullying $(\beta=-0.015, S E=0.017, p=.384)$ and victimization $(\beta=0.018, S E=0.018, p=.313)$.

Table 2 shows that there was a significant main effect of gender, indicating that boys were more likely to bully than girls. Also, a curvilinear age effect was found. The negative beta of the quadratic term implies that the curve for the age effect regarding bullying has an inverted U-shape. The raw data showed that bullying peaks around 9-years old. No other predictors approached significance.

Table 3 shows that for victimization, both gender and classroom sharing appeared to be significant predictors. Boys were more often victim than girls.

As for bullying, a curvilinear age effect was also found for victimization. The negative beta of the quadratic term implies that the curve for the age effect regarding 
TABLE 3

Influences of the (Non) Twin-Specific Factors on Victimization $(n=9,800)^{a}$

\begin{tabular}{|c|c|c|c|c|c|c|}
\hline \multirow[b]{2}{*}{ Covariates } & \multicolumn{2}{|c|}{ Coding } & \multirow[b]{2}{*}{$\beta$} & \multirow[b]{2}{*}{ SE } & \multirow[b]{2}{*}{$p$ value } & \multirow[b]{2}{*}{$\alpha$ level $^{b}$} \\
\hline & 0 & 1 & & & & \\
\hline Gender & Male & Female & -0.236 & 0.029 & $<.001$ & 0.008 \\
\hline Zygosity & $\mathrm{MZ}$ & DZ & 0.052 & 0.037 & .164 & \\
\hline Class & Different & Same & -0.128 & 0.030 & $<.001$ & 0.010 \\
\hline Same-sex & Same & Opposite & 0.069 & 0.037 & .059 & $0.017(N S)$ \\
\hline Age & \multicolumn{2}{|c|}{ Continuous variable } & 0.006 & 0.008 & .430 & \\
\hline Age squared & \multicolumn{2}{|c|}{ Continuous variable } & -0.028 & 0.005 & $<.001$ & 0.013 \\
\hline
\end{tabular}

Note: $S E=$ standard error; $N S=$ not significant. ${ }^{a} N=109$ missing values on class-variable.

${ }^{b}$ Corrected $\alpha$ level according to the Holm- Bonferroni method (Holm, 1979).

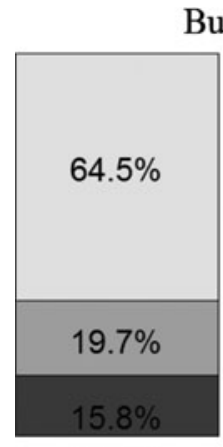

Same
Bullying

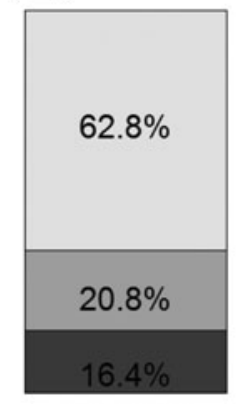

Separate

Classrooms

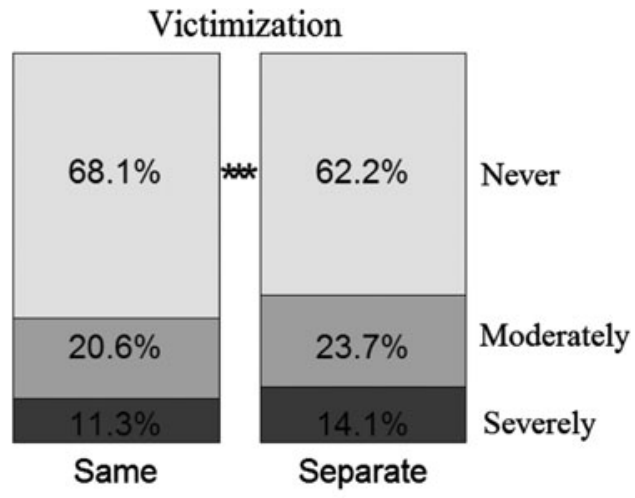

Classrooms

\section{FIGURE 1}

Prevalence rates of bullying and victimization for twins attending same and different classes. Twins in the same classroom do not bully more often (left panel), but are bullied less often than those in separate classrooms (right panel). Follow-up analyses showed that this effect only holds for girl-girl twin pairs.

victimization has an inverted U-shape. The raw data showed that the score peaked around age 9 , so this pattern for victimization mirrors that of bullying. With respect to the twin-specific factors, the significant main effect of classroom sharing indicates that twins attending the same class were less often a victim than those in separate classes. This effect is shown in Figure 1. Due to a possible non-random assignment of twins to same or separate classrooms, we redid the analysis, taking SES and pre-existing differences in externalizing and internalizing problems into account. After controlling for these possible confounders, classroom placement still had an effect of similar magnitude $(\beta=-0.138, S E=0.036, p<.001)$. The other predictors, zygosity, and gender composition, were not significant. In the follow-up analysis, we explored possible interaction effects.

\section{Interaction Results}

The subsequent analysis showed that for boy-boy twins there is no effect of classroom sharing $(\beta=-0.002, S E=$ $0.044, p=.967$ ). Compared to boy-boy twins, the effect of classroom sharing does not differ for opposite-sex twins ( $\beta$ $=-0.062, S E=0.055, p=.261)$, but does for girl-girl twins $(\beta=-0.335, S E=0.057, p<.001)$, indicating that the classroom effect only holds for girl-girl twin pairs. This effect can also be seen in Table 4 .

The second interaction term showed that the effect of gender decomposition (same vs. opposite) does not change as children age with respect to bullying $(\beta=-0.019, S E=$ $0.016, p=.216)$ and victimization $(\beta=-0.011, S E=0.016$, $p=.475)$. The third interaction term showed that the effect of classroom sharing does not differ for $\mathrm{MZ}$ and $\mathrm{DZ}$ twins for bullying $(\beta=-0.090, S E=0.064, p=.159)$ and victimization $(\beta=-0.019, S E=0.064, p=.772)$.

\section{Discussion}

The goal of this study was to advance knowledge about protective and risk factors for bullying and victimization. By addressing important questions about twin-singleton differences and the influences of twin-specific characteristics, we examined whether having a close companion during childhood increases or decreases risk of victimization and bullying. We report no twin-singleton difference, but do show that girl-girl twins are bullied less often when placed in the same classroom. Gender composition of the twin pair 
TABLE 4

Victimization Rates for Girl-Girl, Boy-Boy and Opposite Sex-Twin Pairs in Same Versus Separate Classrooms

\begin{tabular}{lllll}
\hline & & \multicolumn{3}{c}{ Victimization } \\
\cline { 3 - 5 } & & Never (\%) & Moderate (\%) & Severe (\%) \\
\hline \multirow{2}{*}{ Girl-girl } & Separate & 66.5 & 22.8 & 10.7 \\
& Same & 73.8 & 18.1 & 8.1 \\
Boy-boy & Separate & 60.0 & 24.1 & 15.8 \\
& Same & 63.8 & 22.5 & 13.7 \\
Opposite sex & Separate & 60.1 & 24.2 & 15.7 \\
& Same & 66.5 & 21.4 & 12.1 \\
\hline
\end{tabular}

(same vs. opposite sex) and twins' zygosity (MZ vs. DZ) had no effect.

Our finding that twins are not at a higher or lower risk than singletons for bullying and victimization is in agreement with one of the three studies about twin-singleton differences regarding victimization (Oshima et al., 2010). Our finding, however, is inconsistent with the results of Barnes and Boutwell (2013) and Weissenberg et al. (2007), which showed higher risk and lower risk for twins, respectively. The comparison between the studies, though, is hampered by the use of unrelated singletons, which do not match on important family background factors. The first two studies (Oshima et al., 2010; Weissenberg et al., 2007) had power problems as well. Our study reduces both limitations by using large groups of twins and their non-twin siblings. Given the large sample size and the non-significant result, it can be concluded that no twin-singleton differences exist in prevalence rates regarding bullying and victimization. This finding supports the generalizability of twin studies regarding bullying and victimization to the non-twin population.

We furthermore, showed that boys were significantly more likely to bully and to be victimized than girls and that the risk for both bullying and victimization peaks around $8-9$ years. With respect to gender, this result is in line with the body of the literature on bullies (e.g., Bowes et al., 2013) and victims (e.g., Sentse et al., 2015; Takizawa et al., 2014). For age, the existing literature was less clear. Some studies showed that the victimization decreases as children age (e.g., Sapouna, 2008), while others showed the opposite (Atik \& Güneri, 2013). Bullying seems to be more stable. The current study, however, found a significant curvilinear age effect for both traits, showing that the risk for both traits peaks around 8-9 years. Although the effect of gender is large, the effect of age is rather small.

The risk for bullying and victimization is not influenced by twins' zygosity and the gender composition of the twin pairs. This is in line with previous studies that show no effect of twins' zygosity on involvement in bullying, either as bully or victim (e.g., Ball et al., 2008). Also for traits related to bullying, such as reactive and proactive aggression, no zygosity differences exist (Lamarche et al., 2007). Regarding gender composition, Lamarche et al. (2006) found that 6-year-old twins of opposite sex are bullied more often. Our results, however, suggested that for both bullying and victimization same- versus opposite-sex twins do not differ. Their study included 246 twin pairs, while we had the advantage of a nearly 20 -times larger sample. In addition, they did not correct for multiple testing. For related phenotypes, such as social independence, friendship, and behavior problems, no effect of gender composition has been found as well (Laffey-Ardley \& Thorpe, 2006), which supports our results.

We hypothesized that the effect of gender composition is absent at the beginning and present at the end of primary school, given that children increasingly play with same-sex peers (Rose \& Rudolph, 2006). However, we found no interaction and concluded that the effect of gender composition does not change as children age.

The most notable finding of our study was that twin pairs who attend the same classroom do not bully more or less than separated pairs, but they seem to be less victimized. This effect is restricted to girl-girl twin pairs, independent of zygosity, as it does not hold for boy-boy twin pairs or twin pairs of opposite sex. We know of only one study that investigated classroom effects regarding victimization (Lamarche et al., 2006). This study seemed to indicate that classroom sharing has a protective effect against victimization; however, their study and the effect size of the classroom effect were probably too small to reach significance. With our large sample, the difference in victimization scores did reach significance. The finding that girl-girl twins in the same classroom are bullied less often seems to indicate that classroom sharing has a protective effect for victimization. DiLalla and Mullineaux (2008) showed a protective effect of classroom sharing on peer problems as well; their peerproblems scale included one item (out of four items) about victimization. The protective effect of classroom sharing on victimization might be explained by, for instance, children's self-esteem. It is known that victims of bullying often suffer from low self-esteem (O’Moore \& Kirkham, 2001). Girl twins in the same classroom might feel more self-confident by having a sister by their side and are consequently less vulnerable for bullies. Another possible explanation might be the existence of sibling gender composition differences in the sibling relationship quality. The sibling relationship quality is best for girl-girl dyads (Buist, 2010), which might explain why the protective classroom effect is only present for girl-girl twin pairs. It is known that MZ twins are more likely than DZ twins to rate their co-twin as their bestfriend (Foy et al., 2001), but apparently this did not lead to a more pronounced classroom effect for MZ twins.

The result that girl-girl twins in the same classroom tend to be less victimized should be interpreted against the background of non-random classroom assignment. For example, the class assignment could have been influenced by preexisting cognitive, emotional, and behavioral differences between the twins or other external factors. Indeed, van Leeuwen et al. (2005) showed that Dutch twin pairs from 
high SES families are more often separated. In addition, they showed that classroom assignment in the Netherlands is based on early childhood externalizing but not internalizing symptoms. However, after controlling for SES and preexisting differences in externalizing and internalizing problems at age 3 , we showed that classroom sharing still had a protective effect of similar magnitude. This indicates that the protective effect of classroom sharing on victimization holds when taking factors linked to non-random classroom assignment into account.

To further investigate classroom assignment, we looked at the data of a small subsample ( $n=66$ twin pairs) who answered the question 'Who decided to separate the twins?' The answer options of 'school', 'parents', and 'parents in agreement with the school' were each chosen by one-third of the sample. This indicates that assignment of twins to the same or separate classrooms is not systematic. We can conclude that the decision is at least not entirely based on childspecific characteristics.

Notably, from all twin-specific factors discussed, classroom sharing is the only malleable factor. Classroom sharing is a malleable factor for schools that are large enough to have parallel year groups. Schools may have a set policy regarding classroom placement of twins (Saudino et al., 2005), depending on national context and beliefs of the principle and teachers. Nevertheless, most young twins and their parents prefer not to be separated (Gordon, 2015; Staton et al., 2012). The protective effect of classroom sharing regarding victimization for girl-girl twins should be taken into account when twins enter primary school. We furthermore, showed that twins in the same classroom do not bully more often. This is in line with our earlier findings that twins in the same classroom do not differ from twins in separate classrooms for other phenotypes as well, such as academic achievement, problem behavior (Polderman et al., 2010; van Leeuwen et al., 2005), and academic motivation (Kovas et al., 2015). Taken together, the placement of twins in the same classroom might be beneficial regarding victimization and is not harmful for other important behavioral outcomes.

While interpreting the results of our study, it is important to acknowledge that bullying and victimization is based on teacher ratings and thus applies to the daily school setting. It is known that teachers do not necessarily rate bullying behavior in the same way as parents and children themselves do (Rønning et al., 2009), with agreement correlation in the range of $0.18-0.19$ for bullying and $0.11-0.22$ for victimization. Using teacher-reported data is, however, not necessarily a disadvantage, since the view of teachers might be more objective.

Future research might investigate the extent to which twin separation at school entry is random. A true randomized control trial, in which researchers decide whether a twin pair will be separated or not, will face ethical resistance. We can, however, ask the teacher whether their school has a set policy regarding classroom assignment of twins. For the subset of schools that are large enough to have parallel year groups and that have set policies, whether a twin pair attends the same or different classes ought not to be related to child characteristics. Therefore, such a prospective study comes closer to a randomized trial. Follow-up research could also focus on the protective effect of these girl-girl twins attending the same classrooms and try to uncover the underlying mechanisms. To speculate, this protective effect might be due to girl-girl twins feeling more self-confident when studying in the same classroom, which might not be the case for boy-boy and oppositesex twins. It is well known that more self-confidence makes children less prone to be a victim of peer bullying. Although further research is needed to elucidate the mechanisms, this finding in itself offers an important new perspective on the question if twin pairs should be separated or not.

To conclude, we demonstrate that assigning twins to the same classroom seems to have a protective effect for girlgirl twins, but not for boy-boy or opposite-sex twins. Importantly, girl-girl twins in the same classroom do not bully more often. Our result indicates that it might be beneficial to keep girl-girl twins together when entering primary school.

\section{Acknowledgments}

We are grateful to the twin families and the teachers for their participation. This research was supported by 'Spinozapremie' (NWO/SPI 56-464-14192); 'Twin-family database for behavior genetics and genomics studies' (NWO 48004-004); Genetics of Mental Illness: European Research Council (ERC-230374); Genetic influences on stability and change in psychopathology from childhood to young adulthood (NWO/ZonMW 91210020). EvB is supported by a VENI fellowship (NWO 451-15-017). The research conducted for this manuscript is part of The Consortium on Individual Development (CID), which is funded through the Gravitation program of the Dutch Ministry of Education, Culture, and Science and the Netherlands Organization for Scientific Research (NWO grant number 024.001.003).

\section{References}

Atik, G., \& Güneri, O. Y. (2013). Bullying and victimization: Predictive role of individual, parental, and academic factors. School Psychology International, 34, 658-673.

Ball, H. A., Arseneault, L., Taylor, A., Maughan, B., Caspi, A., \& Moffitt, T. E. (2008). Genetic and environmental influences on victims, bullies and bully-victims in childhood. Journal of Child Psychology and Psychiatry, 49, 104-112.

Barnes, J. C., \& Boutwell, B. B. (2013). A demonstration of the generalizability of twin-based research on antisocial behavior. Behavior Genetics, 43, 120-131.

Bowes, L., Maughan, B., Ball, H., Shakoor, S., Ouellet-Morin, I., Caspi, A., ... Arseneault, L. (2013). Chronic bullying vic- 
timization across school transitions: The role of genetic and environmental influences. Development and Psychopathology, 25, 333-346.

Brendgen, M., Boivin, M., Vitaro, F., Dionne, G., Girard, A., \& Pérusse, D. (2008). Gene-environment interactions between peer victimization and child aggression. Development and Psychopathology, 20, 455-471.

Buist, K. L. (2010). Sibling relationship quality and adolescent delinquency: A latent growth curve approach. Journal of Family Psychology, 24, 400-410.

Camodeca, M., Goossens, F. A., Terwogt, M. M., \& Schuengel, C. (2002). Bullying and victimization among school-age children: Stability and links to proactive and reactive aggression. Social Development, 11, 332-345.

DiLalla, L. F. (2006). Social development of twins. Twin Research and Human Genetics, 9, 95-102.

DiLalla, L. F., \& Mullineaux, P. Y. (2008). The effect of classroom environment on problem behaviors: A twin study. Journal of School Psychology, 46, 107-128.

Foy, A. K., Vernon, P. A., \& Jang, K. (2001). Examining the dimensions of intimacy in twin and peer relationships. Twin Research, 4, 443-452.

Gini, G., \& Pozzoli, T. (2009). Association between bullying and psychosomatic problems: A meta-analysis. Pediatrics, 123, 1059-1065.

Goldbaum, S., Craig, W. M., Pepler, D., \& Connolly, J. (2003). Developmental trajectories of victimization: Identifying risk and protective factors. Journal of Applied School Psychology, 19, 139-156.

Gordon, L. M. (2015). Twins and kindergarten separation: Divergent beliefs of principals, teachers, parents, and twins. Educational Policy, 29, 583-616.

Griffin, R. S., \& Gross, A. M. (2004). Childhood bullying: Current empirical findings and future directions for research. Aggression and Violent Behavior, 9, 379-400.

Hawker, D. S., \& Boulton, M. J. (2000). Twenty years' research on peer victimization and psychosocial maladjustment: A meta-analytic review of cross-sectional studies. Journal of Child Psychology and Psychiatry, 41, 441-455.

Hay, D. A., \& Preedy, P. (2006). Meeting the educational needs of multiple birth children. Early human development, 82, 397-403.

Hodges, E. V., Boivin, M., Vitaro, F., \& Bukowski, W. M. (1999). The power of friendship: Protection against an escalating cycle of peer victimization. Developmental Psychology, 35, 94-101.

Holm, S. (1979). A simple sequentially rejective multiple test procedure. Scandinavian Journal of Statistics, 6, 65-70.

Jansen, P. W., Verlinden, M., Dommisse-Van Berkel, A., Mieloo, C., Van der Ende, J., Veenstra, R., ... Tiemeier, H. (2012). Prevalence of bullying and victimization among children in early elementary school: Do family and school neighborhood socioeconomic status matter? BMC Public Health, 12, 494.

Kokkinos, C. M., \& Antoniadou, N. (2013). Bullying and victimization experiences in elementary school students nominated by their teachers for specific learning disabilities. School Psychology International, 34, 674690.

Kovas, Y., Garon-Carrier, G., Boivin, M., Petrill, S. A., Plomin, R., Malykh, S. B., ... Tremblay, R. (2015). Why children differ in motivation to learn: Insights from over 13,000 twins from 6 countries. Personality and Individual Differences, 80, 51-63.

Laffey-Ardley, S., \& Thorpe, K. (2006). Being opposite: Is there advantage for social competence and friendships in being an opposite-sex twin? Twin Research and Human Genetics, 9, 131-140.

Lamarche, V., Brendgen, M., Boivin, M., Vitaro, F., Dionne, G., \& Pérusse, D. (2007). Do friends' characteristics moderate the prospective links between peer victimization and reactive and proactive aggression? Journal of Abnormal Child Psychology, 35, 665-680.

Lamarche, V., Brendgen, M., Boivin, M., Vitaro, F., Pérusse, D., \& Dionne, G. (2006). Do friendships and sibling relationships provide protection against peer victimization in a similar way? Social Development, 15, 373-393.

Muthén, L. K., \& Muthén, B. O. (1998-2012). Mplus user's guide (7th ed.). Los Angeles, CA: Muthén \& Muthén.

O'Moore, M., \& Kirkham, C. (2001). Self-esteem and its relationship to bullying behaviour. Aggressive Behavior, 27, 269-283.

Oshima, N., Nishida, A., Fukushima, M., Shimodera, S., Kasai, K., Okazaki, Y., \& Sasaki, T. (2010). Psychotic-like experiences (PLEs) and mental health status in twin and singleton Japanese high school students. Early Intervention in Psychiatry, 4, 206-213.

Pellegrini, A. D., \& Long, J. D. (2002). A longitudinal study of bullying, dominance, and victimization during the transition from primary school through secondary school. British Journal of Developmental Psychology, 20, 259-280.

Polderman, T. J., Bartels, M., Verhulst, F. C., Huizink, A. C., van Beijsterveldt, C. E., \& Boomsma, D. I. (2010). No effect of classroom sharing on educational achievement in twins: A prospective, longitudinal cohort study. Journal of Epidemiology and Community Health, 64, 36-40.

R Core Team. (2015). R: A language and environment for statistical computing. Vienna, Austria: R Foundation for Statistical Computing.

Rønning, J. A., Sourander, A., Kumpulainen, K., Tamminen, T., Niemelä, S., Moilanen, I., ... Almqvist, F. (2009). Crossinformant agreement about bullying and victimization among eight-year-olds: Whose information best predicts psychiatric caseness 10-15 years later? Social Psychiatry and Psychiatric Epidemiology, 44, 15-22.

Rose, A. J., \& Rudolph, K. D. (2006). A review of sex differences in peer relationship processes: Potential trade-offs for the emotional and behavioral development of girls and boys. Psychological Bulletin, 132, 98-131.

Sapouna, M. (2008). Bullying in Greek primary and secondary schools. School Psychology International, 29, 199-213.

Saudino, K. J., Ronald, A., \& Plomin, R. (2005). The etiology of behavior problems in 7-year-old twins: Substantial genetic influence and negligible shared environmental 
influence for parent ratings and ratings by same and different teachers. Journal of Abnormal Child Psychology, 33, 113-130.

Sentse, M., Kretschmer, T., \& Salmivalli, C. (2015). The Longitudinal Interplay between bullying, victimization, and social status: Age-related and gender differences. Social Development, 24, 659-677.

Shakoor, S., McGuire, P., Cardno, A. G., Freeman, D., Plomin, R., \& Ronald, A. (2015). A shared genetic propensity underlies experiences of bullying victimization in late childhood and self-rated paranoid thinking in adolescence. Schizophrenia Bulletin, 41, 754763.

Staton, S., Thorpe, K., Thompson, C., \& Danby, S. (2012). To separate or not to separate? Parental decision-making regarding the separation of twins in the early years of schooling. Journal of Early Childhood Research, 10, 196208.

Takizawa, R., Maughan, B., \& Arseneault, L. (2014). Adult health outcomes of childhood bullying victimization: Evidence from a five-decade longitudinal British birth cohort. American Journal of Psychiatry, 171, 777-784.
Tancredy, C. M., \& Fraley, R. C. (2006). The nature of adult twin relationships: An attachment-theoretical perspective. Journal of Personality and Social Psychology, 90, 78-93.

Van Beijsterveldt, C. E., Groen-Blokhuis, M., Hottenga, J. J., Franić, S., Hudziak, J. J., Lamb, D., ...Boomsma, D. I. (2013). The Young Netherlands Twin Register (YNTR): Longitudinal twin and family studies in over 70,000 children. Twin Research and Human Genetics, 16, 252-267.

Van Leeuwen, M., van den Berg, S. M., van Beijsterveldt, T. C., \& Boomsma, D. I. (2005). Effects of twin separation in primary school. Twin Research and Human Genetics, 8, 384391.

Von Marées, N., \& Petermann, F. (2010). Bullying in German primary schools gender differences, age trends and influence of parents' migration and educational backgrounds. School Psychology International, 31, 178-198.

Weissenberg, R., Landau, R., \& Madgar, I. (2007). Older single mothers assisted by sperm donation and their children. Human Reproduction, 22, 2784-2791.

Williams, R. L. (2000). A note on robust variance estimation for cluster-correlated data. Biometrics, 56, 645-646. 